\title{
Growing through adolescence: a gendered approach is needed
}

\author{
Joanna C. Inchley ${ }^{1}$
}

Received: 23 January 2019/Accepted: 25 January 2019/Published online: 10 February 2019

(C) Swiss School of Public Health (SSPH+) 2019

Adolescents now make up more than a quarter of the world's population, largely due to significant reductions in child mortality in recent decades (Sawyer et al. 2012). Adolescence represents the years between childhood and adulthood, encompassing attainment of physical and sexual maturity and increasing social independence. It is a stage of extensive neurological development which is known to be particularly sensitive to environmental exposures. At the same time, young people experience major social transitions in different spheres of their lives, including family, school and peer relations, and the impact of these is in turn influenced by wider sociocultural, political and economic factors. These transitions all interact to "modify childhood trajectories towards health and wellbeing" (Viner et al. 2012). It is not surprising, therefore, that the second decade of life is now recognised as a key opportunity for investment and intervention (WHO 2014). Traditionally a neglected phase of the life course, there has been a renewed public health focus on adolescence in recent years which is to be welcomed.

This special issue brings together a wide range of research on adolescent transitions, reflecting the diversity and complexity of young people's lives today. While we have seen significant public health improvements in some areas in recent years, such as marked declines in smoking and drinking among adolescents in many developed countries (Inchley et al. 2018), many challenges still need to be addressed including worsening mental health (Collishaw 2015), high levels of overweight and obesity (Lobstein et al. 2015) and increasingly sedentary lifestyles (Bucksch et al. 2016).

The current generation of young people are growing up in an era of rapid change with major societal shifts such as

This Editorial is part of the special issue "Adolescent transitions".

Joanna C. Inchley

jci2@st-andrews.ac.uk

1 School of Medicine, University of St Andrews, St Andrews, Fife KY16 9TF, UK increasing globalisation, urbanisation, migration and digitalisation all changing the landscape of adolescents' lives. These global trends introduce both opportunities and challenges for young people's healthy development. Within this wider social context, what does a 'healthy adolescence' mean and how can a gendered approach help us to better address the needs of young people today?

Several of the papers in this Special Issue highlight important gender differences in health and health behaviours. For example, Miranda-Mendizabal et al. (2019) conducted a systematic review of longitudinal studies of suicide behaviours and found higher prevalence of suicide attempt among females but higher prevalence of suicide death among males. These differences are well-established but interestingly the authors also found that many of the key risk factors for suicidal behaviour were gender-specific. Similarly, the studies by Hyun-soo Kim (2018) and Farrell et al. (2018) also identified gender differences in risk factors for suicide behaviours across diverse sample populations. In relation to other health outcomes, Moreau et al. (2018) report higher prevalence of negative feelings about timing of first sexual intercourse among girls than boys in a European sample, Sadalla Collese et al. (2018) found gender differences in clustering of energy-related behaviours among both Brazilian and European adolescents, and Paclikova et al. (2018) found a moderating effect of gender on the relationship between family communication and emotional and behaviour problems in Slovak adolescents.

A number of the studies in this issue have used data from the Health Behaviour in School-aged Children (HBSC) survey, a WHO collaborative cross-national study of adolescent health and wellbeing in Europe and North America. This study provides unique insights into temporal changes in adolescent health and health behaviour over the last $30+$ years, as well as the ability to interrogate individual- and country-level differences in health outcomes. The most recent HBSC international report (Inchley et al. 2016) highlighted marked gender inequalities during the adolescent years, many of which worsen with age and have persisted over time. Boys, for example, are more likely to 
engage in health-compromising behaviours such as alcohol use, smoking and fighting, but report higher levels of selfrated health, physical activity and breakfast consumption. Girls, on the other hand, are more likely to report health complaints and poor body image but higher levels of fruit and vegetable consumption and tooth brushing. HBSC and other research have also shown consistent gender differences in the social determinants of health, including social relations and school experience.

Such systematic disparities demonstrate the need for gender-sensitive preventive approaches which take account not only of differences in health outcomes but also in health determinants. Gender norms and roles which are shaped by societal expectations can affect both exposure and vulnerability to health risks during adolescence. Further, more research is needed to understand the specific health needs of young people who identify as transgender or non-binary to ensure that they have access to appropriate services and support. Targeted public health policies and programmes are required to enable all young people to thrive and fulfil their potential as they navigate the developmental challenges of the adolescent years.

\section{References}

Bucksch J, Sigmundova D, Hamrik Z et al (2016) International trends in adolescent screen-time behaviours from 2002-2010. J Adol Health 58:417-425

Collese TS, De Moraes AC, Fernandez-Alvira JM, Michels N, De Henauw S, Manios Y, Androutsos O, Kafatos A, Widhalm K, Galfo M, Beghin L, Sjostrom M, Pedrero-Chamizo R, Carvalho H, Moreno L (2018) How do energy balance-related behaviors cluster in adolescents? Int J Public Health. https://doi.org/10. 1007/s00038-018-1178-3

Collishaw S (2015) Annual research review: secular trends in child and adolescent mental health. J Child Psychol and Psychiatry 56(3):370-393

Farrell CT, Moledina Z, Katta MS (2018) Suicidal thoughts in lowincome adolescents: a longitudinal analysis. Int J Public Health. https://doi.org/10.1007/s00038-018-1169-4
Inchley J, Currie D, Young T, Samdal O, Torsheim T, Auguston L, Mathison F, Aleman-Diaz A, Molcho M, Weber M, Barnekow V (eds) (2016) Growing up unequal: gender and socioeconomic differences in young people's health and well-being. Health Behaviour in School-aged Children (HBSC) study: international report from the 2013/2014 survey. WHO Regional Office for Europe, Copenhagen (Health Policy for Children and Adolescents, No. 7)

Inchley J, Currie D, Vieno A, Torshiem T, Ferriera-Borges C, Weber MM, Barnekow V, Breda J (2018) Adolescent alcohol-related behaviours: trends and inequalities in the WHO European Region, 2002-2014. WHO Regional Office for Europe, Copenhagen

Kim H-S (2018) Parental overprotection and youth suicide behaviour in low and middle-income countries: a multilevel analysis of cross-national data. Int J Public Health. https://doi.org/10.1007/ s00038-018-1169-4

Lobstein T, Jackson-Leach R, Moodie ML et al (2015) Child and adolescent obesity: part of a bigger picture. Lancet 385(9986):2510-2520

Miranda-Mendizabal A, Castellvi P, Pares-Badell O et al (2019) Gender differences in suicidal behaviour in adolescents and young adults: systematic review and meta-analysis of longitudinal studies. Int J Public Health. https://doi.org/10.1007/ s00038-018-1196-1

Moreau N, Kolto A, Young H, Maillochon F, Godeau E (2018) Negative feelings about the timing of first sexual intercourse: findings from the health behaviour in school-aged children study. Int J Public Health. https://doi.org/10.1007/s00038-018-1170-y

Paclikova K, Veselska ZD, Bobakova DF, Palfiova M, Geckova AM (2018) What role do family composition and functioning play in emotional and behavioural problems among adolescent boys and girls? Int J Public Health. https://doi.org/10.1007/s00038-0181171-x

Sawyer SM, Afifi RA, Bearinger LH, Blakemore S-J, Dick B, Ezeh AC, Patton GC (2012) Adolescence: a foundation for future health. Lancet 379:1630-1640

Viner RM, Ozer EM, Denny S, Marmot M, Resnick M, Adesegun F, Currie C (2012) Adolescence and the social determinants of health. Lancet 379:1641-1652

WHO (2014) Health for the World's adolescents: a second chance in the second decade. World Health Organisation, Geneva

Publisher's Note Springer Nature remains neutral with regard to jurisdictional claims in published maps and institutional affiliations. 